\title{
Evidence Based Policy Gaps in Water Resources: Thinking Fast and Slow on Floods and Flow
}

\author{
Robert J. Muir \\ Corporation of the City of Markham, Markham, Ontario.
}

\section{Editor's Note}

This thought provoking paper does not readily fit any of the categories of our usual papers. We believe that the paper will interest readers concerned about the easy adoption of standardised design methodologies and regionalised hydrological parameters. Importantly, the paper implies that there is now a greater need for research and development at the municipal scale. It is our hope that readers will contribute to this debate, especially in this age of controvertible methodologies for sustainable human development.

\begin{abstract}
Water resources management and municipal engineering practices have matured in Canada over recent decades. Each year, more refined analytical tools are developed and used in urban flood management. We are now at a state where practitioners must use these tools within broad decision making frameworks to address system risks and the life cycle economics of prescribed solutions. Otherwise, evidence based policy gaps in the prioritization of risk factors and damages will widen and lead to misdirected mitigation efforts. For example, despite statistically significant decreases in regional short duration rainfall intensities in Southern Ontario, extensive resources are devoted to projecting IDF curves under climate change. Thinking fast, as defined by Daniel Kahneman, through listing recent extreme events to declare new weather reality risks based on heuristic availability biases, has replaced data driven policy and the statistical rigour of thinking slow problem solving. Under this skewed risk perspective, a high profile Ontario commuter train flood was mischaracterized as an unprecedented event despite a $<5$ y return period and a greater flood weeks before. Recent Ontario urban flood incidents have been attributed to unprecedented weather despite GIS analysis showing more critical hydrologic drivers. Constraints on effective water management are now less likely to be technical but rather scientific (inadequate representation of urban groundwater systems), institutional (arbitrary boundaries between city and watershed agency jurisdictions), economic (unaffordable green infrastructure solutions based on cost-benefit analysis and flat normalized loss trends), or operational. Evidence based policies and water management solutions are needed from a broad risk and economic framework that recognizes these barriers and uncertainties in the application of analytic tools.
\end{abstract}

\section{Evidence Based Policy}

\subsection{Public Policy Origins}

Evidence based policy has been defined as public policy that is informed by rigorously established and objective evidence. The primary goal of such policy is to improve the reliability of advice and the efficiency and effectiveness of recommended alternatives (Head 2010). It also serves to counter ideologically driven decision making that may rely on subjective values and limited statistical data or scientific knowledge. Evidence based policy approaches have been embraced by governments around the globe as a means of improving the delivery of vital public services (Bullock et al. 2001).

In flood risk management in Canada, the need for evidence based policy stems from the increasing complexity of the systems being analysed, which include uncertainty surrounding risk factors and model representations of physical processes, limited cost-benefit considerations, physical and financial constraints on the implementation of remediation solutions, and tradeoffs between diverging water management goals. The need for comprehensive cost-benefit analysis to guide flood mitigation was first proposed in Canada in the 1956 Manitoba Commission on Flood Cost Benefit, pioneering a new approach and methodology for planning and public policy (Bumstead 2002). Today, in the face

Muir, Robert J. Evidence Based Policy Gaps in Water Resources: Thinking Fast and Slow on Floods and Flow.

2018. Journal of Water Management Modeling 26:C449. https://doi.org/10.14796/JWMM.C449

(c) CHI 2018. www.chijournal.org ISSN 2292-6062. 
of increasing complexities and finite financial resources, evidence based policies derived through comprehensive studies are paramount. Robust decision support systems have been developed for complex infrastructure systems with uncertain behaviour and high remediation costs (James et al. 1998), yet the application of such approaches is often not practiced.

\subsection{Risk Based Approaches}

Ontario practitioners have developed and embraced methodical, evidence based and risk based approaches to water management. This includes the Municipal Class Environmental Assessment (MCEA) process used for the planning and implementation of municipal infrastructure projects (MEA 2015). At the core of this process is the identification of project schedules that rank the risks and impacts of the undertaking and that guide the required level of detail in alternative development, the evaluation of impacts and mitigation, consultation, and documentation. The process requires the definition of a problem statement to identify a problem, deficiency or opportunity and it prescribes a systematic, traceable approach to establish a preferred solution that considers broad technical, economic, social and environmental impacts. The process recognizes the importance of local conditions in defining existing problems, risks and solutions.

Following the Walkerton, Ontario tragedy in May 2000 in which seven people died and thousands were sickened due to E. Coli contamination of a municipal well supply, the Walkerton Inquiry recommended a risk based approach to ensuring drinking water safety. The Commission's Part 2 Report noted:

The key features of a good approach to managing risk include being preventive rather than reactive; distinguishing greater risks from lesser ones, and dealing first with the former; taking time to learn from experience; and investing resources in risk management that are proportional to the danger posed.

O'Connor 2002

Subsequent implementation of local source water protection plans incorporated risk based water quality and quantity management policies. Water quantity management policies were developed by first considering the intrinsic vulnerabilities of different classes of water supply sources, and second by following a tiered analysis regime to assess water quantity stresses with progressively advanced modeling tools and evaluation scenarios.

Source protection policies have helped to illustrate the multi-objective and sometimes diverging nature of water management goals. For example, in considering the goals of aquifer water quantity management and aquifer water quality protection, the infiltration of stormwater runoff through implementation of low-impact-development (LID) infiltration measures can be viewed as either a positive recharge opportunity or a negative contaminant pathway. As a result, policies are refined based on local conditions, balancing adverse impacts and risks as well as benefits.

\subsection{Thinking, Fast and Slow}

Thinking, Fast and Slow by Nobel laureate Daniel Kahneman explores cognitive biases that influence the way that humans often solve problems (Kahneman 2011). Central to the discussion is the distinction between two modes of thought described as the fast System 1 that is instinctive, emotional and error-prone, and the slow System 2 that is analytical, methodical and reliable. System 2 thinking is consistent with an evidence based data driven approach to problem solving and policy development. System 1 thinking is characterized by heuristic biases that, in the case of urban flood risk management, can result in poorly framed problem statements, inaccurate risk assessment and ill-defined solutions.

Thinking fast heuristic biases are many and include the anchoring bias, or focalism, which is the common human tendency to rely too heavily on the first piece of information offered (the anchor) when making decisions, as opposed to a full and complete set of information. Another is the availability heuristic, a mental shortcut that occurs when judgments about the probabilities of events are made based on how easy it is to think of examples of events. Attribute substitution is another cognitive bias in the problem solving process that occurs when an individual has to make a judgment about a target attribute that would be computationally complex and instead substitutes a more easily calculated judgement about a different heuristic attribute. The individual solving the problem is not aware that a substitution has taken place.

These biases can limit the effectiveness of water management decision making at a time when evidence based policies for asset management and infrastructure investment are being embraced. Ontario's Building Better Lives: Long-Term Infrastructure Plan 2017 notes that "The government needs strong evidence to ensure the right infrastructure is built in the right place at the right time in communities across Ontario," citing the need to apply a risk lens to assess vulnerabilities to support infrastructure planning and design (Ontario Ministry of Infrastructure 2017).

\subsection{Ideology and Scope Bias: What You See Is All There Is}

In the face of complex water resources management challenges, practitioners may or may not have a wide choice in how they approach problem solving and decision making. A water management study that is commissioned under the Ontario MCEA process may have well-defined approaches that help ensure rigorous analysis and a consistent, reliable solution. However, the scope of the analysis may not necessarily be robust, and can be dictated by what is defined in a client's request for proposal, based on their understanding of the risk factors and potential solutions. Similarly, proposals to conduct research into effective flood mitigation measures may be defined by a funding agency's interests and anticipated solutions (e.g. to define the return on investment of wetland preservation in terms of flood mitigation 
in Ontario cities, when wetlands may not in fact represent the greatest opportunity for return on investment).

Within a defined and perhaps restricted scope of project analysis, heuristic biases can emerge. Consider a wide-reaching water resources initiative such as green infrastructure (Gl): low impact development (LID) implementation policies have significant economic impacts, and require complex economic analysis through a detailed assessment of full life cycle capital cost and operation and maintenance costs within a complex range of physical settings and constraints. Instead of approaching the complex economic analysis with an evidence based System 2 approach, an unreliable System 1 approach might be taken. The non-analytical System 1 approach could lead to an ill founded economic decision due to a multitude of biases, including: anchoring bias, by extrapolating limited case study economics applicable only to isolated physical settings to the broad initiative and broader diverse settings; the availability heuristic, by assuming the technical feasibility of a few readily-recalled demonstration technologies that would then also characterize feasibility at a significantly wider system scale; and attribute substitution, by assuming that local technology performance for a limited set of attributes would result in system-wide performance benefits for a somewhat related set of attributes.

Kahneman describes a pervasive optimism bias which is also described as unwarranted optimism, or a planning fallacy, that tends to overestimate benefits and underestimate costs which can impede evidence based analyses and policy development. He explains this overconfidence bias with the concept of What You See Is All There Is (WYSIATI). In this manner, a decision maker deals with the known knowns that they are familiar with, deals less with the known unknowns, or uncertainties, of an undertaking, and may ignore the unseen, out-of-scope surrounding a decision. In the case of a GI or LID project proponent, pervasive optimism may surround selected demonstration projects related to a runoff infiltration technology, providing a set of known knowns. Meanwhile, the impact of recharged runoff on partially separated sanitary sewer system infiltration or groundwater quality could be known unknowns in the analysis, thus afforded little or no attention. And the impact of recharged chlorides from the infiltration technology on soil resistivity and external corrosion of existing cast and ductile iron watermains, or impacts to roadway base stability or foundation walls, would be unknown unknowns, receiving no attention in the decision making process.

The WYSIATI bias can be considered through the eyes of water system modelers and planners when analysing water resources systems. These practitioners are in control of defining What You See by framing the scope of the analyses, presenting results, and qualifying the uncertainties in terms of known and unknown. In MCEA studies the WYSIATI bias may be mitigated by embracing a broad set of robust alternatives and by evaluating the negative impacts of a project from a multi-disciplinary perspective, beyond the expected positive impacts.

\section{Heuristic Biases in Water Resources Management}

\subsection{Anchoring Bias: Temperature and Extreme Rainfall Trends}

Trends in extreme rainfall characteristics are at the forefront of urban flood management discussions as increase in extreme rainfall intensity or frequency, if observed, would indicate a greater risk of runoff and flood damage in some systems. Increased rainfall severity has also been associated with increased temperatures due to climate change, because warmer air has a greater water holding capacity than cooler air.

Temperature increases have been observed and documented in Canada, but increased rainfall severity has not. Statistics Canada (2011) data show an increase in mean temperature of $1.4^{\circ} \mathrm{C}$ over the 62 y period 1948-2009, according to Environment Canada's 2010 Climate Trends and Variations Bulletin. Environment Canada data show no overall increasing trends for extreme rainfall:

The single station analysis shows a general lack of a detectable trend signal, at the $5 \%$ significance level; ...

For the shortest durations of $5 \mathrm{~min}$ to $15 \mathrm{~min}$, the general overall regional trends in the extreme amounts are more variable, with increasing and decreasing trends occurring with similar frequency; and ...

This indicates that at most locations across Canada the traditional single station IDF assumption that historical extreme rainfall observations are stationary (in terms of the mean) over the period of record for an individual station is not violated.

Shephard et al. 2014

Notwithstanding these data, Ontario policy documents report that temperatures and rainfall do increase together, which suggests an anchoring bias. For example the Ministry of the Environment and Climate Change's (MOECC) Ontario's Climate Change Discussion Paper (MOECC 2015) states that "Ontario's historical data demonstrates significant changes in our temperature and precipitation trends." This statement on significant changes in precipitation is not, however, supported by local data analysis. A study on intensity-duration-frequency (IDF) estimates in Southern Ontario also reported:

The majority of the trends were determined to be non-significant with no simple patterns or uniform rates of change evident in the short duration rainfall.

Environment Canada 2011

A review of Canada's most recent engineering climate datasets, version 2.3 (Environment and Climate Change Canada 2015) indicates that climate stations with long term records show as many decreasing trends as increasing trends, as shown in Figure 1. 


\begin{tabular}{|c|c|c|c|c|c|c|c|c|c|c|c|c|c|}
\hline \multirow{2}{*}{\multicolumn{2}{|c|}{ Climate Station Name }} & \multirow{2}{*}{ Station ID } & \multicolumn{9}{|c|}{$\begin{array}{l}\text { Engineering Climate Datasets } \\
\text { Annual Maximum Rainfall } \\
\text { Trend and Significance }\end{array}$} & \multirow{2}{*}{$\begin{array}{l}\text { No. of } \\
\text { Years }\end{array}$} & \multirow{2}{*}{$\begin{array}{l}\text { Most } \\
\text { Recent } \\
\text { Year }\end{array}$} \\
\hline & & & $\frac{\varepsilon}{\varepsilon}$ & $\begin{array}{l}\mathrm{E} \\
\frac{\mathrm{E}}{\mathrm{\varepsilon}} \\
\mathrm{O}\end{array}$ & 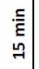 & 高 & 亡 & $\stackrel{!}{n}$ & $\frac{\grave{c}}{6}$ & $\stackrel{亡}{\underset{7}{7}}$ & $\frac{9}{5}$ & & \\
\hline \multicolumn{14}{|l|}{ Ontario } \\
\hline Ear Falls (Aut) & $\mathrm{ON}$ & 6012199 & & & & & & & & & & 49 & 2006 \\
\hline Geraldton A & $\mathrm{ON}$ & 6042716 & & & & & & & & & & 48 & 2006 \\
\hline Thunder Bay CS & $\mathrm{ON}$ & 6048268 & & & & & & & & & & 47 & 2006 \\
\hline Timmins Victor Power A & $\mathrm{ON}$ & 6078285 & & & & & & & & & & 47 & 2006 \\
\hline Kingston Pumping Station & ON & 6104175 & & & & & & & & & & 63 & 2007 \\
\hline Ottawa Cda Rcs & $\mathrm{ON}$ & 6105978 & & & & & & & & & & 50 & 2007 \\
\hline St Thomas Wpcp & $\mathrm{ON}$ & 6137362 & & & & & & & & & & 75 & 2007 \\
\hline Windsor A & $\mathrm{ON}$ & 6139525 & & & & & & & & & & 60 & 2007 \\
\hline London Cs & $\mathrm{ON}$ & 6144478 & & & & & & & & & & 57 & 2007 \\
\hline Toronto City & ON & 6158355 & & & & & & & & & & 59 & 2007 \\
\hline Toronto Intl A & ON & 6158731 & & & & & & & & & & 60 & 2013 \\
\hline
\end{tabular}

Source

Environment Canada Engineering Climate Dataset v2.3

idf_v2-3_2014_12_21_trends.txt

IDF_Additional_Additionnel_v2.30.zip

ftp://ftp.tor.ec.gc.ca/Pub/Engineering_Climate_Dataset/IDF/

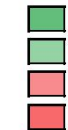

Decreasing extreme rain / Significant Trend Decreasing extreme rain / Not Significant Increasing extreme rain / Not Significant Increasing extreme rain / Significant Trend

Figure 1 Environment Canada engineering climate datasets (version 2.3) annual maximum rainfall trend direction and statistical significance.

In Southern Ontario, among climate stations with latitude below $44^{\circ} \mathrm{N}, 2.3 \%$ of annual maximum series trends show statistically significant decreases, while only $1.0 \%$ of trends show statistically significant increases. Furthermore, for shorter durations of $<6 \mathrm{~h}$, which are critical to urban flood risks, 6 times as many significant decreasing trends were reported than increasing trends. These observations are summarized in Table 1.

Table 1 Southern Ontario observed annual maximum rainfall trends from Environment and Climate Change Canada's engineering climate datasets (version 2.3).

\begin{tabular}{lc}
\hline Maximum Rainfall Trend Direction and Statistical Significance & Percentage of $5 \mathrm{~min}$ to $24 \mathrm{~h}$ Trends \\
\hline Decrease / Significant & $2.3 \%$ \\
Decrease / Not Significant & $39.9 \%$ \\
No Data & $8.7 \%$ \\
Increase / Not Significant & $48.1 \%$ \\
Increase / Significant & $1.0 \%$ \\
\hline
\end{tabular}

Media reports following extreme rainfall events can skew public perception of extreme rainfall trends. Often an anchoring bias is created by referring to historical rainfall statistics on a particular calendar date, or average climatic conditions, in order to increase the reported severity of the weather event. Examples include the 2013-07-08 Toronto storm, where $126.0 \mathrm{~mm}$ rainfall was recorded at Pearson International Airport in Mississauga. The National Post reported "Before Monday, the highest rainfall ever experienced in Toronto for July 8 was $29.2 \mathrm{~mm}$ set in 2008-a record that was more than tripled" (Edmiston 2013). The tripling of a record appears extreme when referring to a particular calendar date and anchors the perception of storm severity. This anchoring statement ignores the fact that particular calendar date statistics are irrelevant to infrastructure design as $\sim 67 \%$ of July days are dry in Toronto. Daily totals of a similar magnitude to 2013-07-08 were recorded twice before, in 1980 (119.9 $\mathrm{mm}$ ) and 1954 (137.4 mm), and the previous July 8 record was exceeded by $200 \%$ in 7 other years between 1950 and 2013. Headlines appear to emphasize the rarity of events, not the commonplace, often by establishing an anchoring bias.

\subsection{Availability Heuristic: Extreme Rainfall Fre- quency}

The probability of extreme rainfall events is readily determined through statistical analysis of observed rainfall characteristics. IDF statistics are derived by fitting probability distributions to the observed values, allowing extreme values to be extrapolated or interpolated according to the distribution. This is the appropriate data driven evidence based analytical System 2 approach.

The likelihood of extreme weather events is sometimes estimated without statistical analysis according to the availability heuristic and an unreliable System 1 approach. For example, a local conservation authority has declared that there are new weather realities, indicating that "the future isn't what it used to be," by citing four extreme events that had occurred in Southern Ontario over an earlier 9 y period. The availability heuristic that supports the declaration of new realities is an analysis shortcut that occurs when a judgment is made concerning the probability of events by how easy it is to think of examples or, in this case, to list previous extreme weather events. It has been suggested that the newsworthiness of a sensational event, such as the abandonment of a lawyer's Ferrari in a Toronto underpass during a flood event, or a stranded commuter train, can assist in the recall of events, contributing to the availability bias.

Turning to more reliable System 2 statistical analyses, Environment and Climate Change Canada's extreme rainfall trend observations point to a new weather reality that is similar to the old weather reality. Furthermore, data show that just as observed annual maximum rainfall amounts have decreased in regions of Canada, so too have the derived extreme rainfall IDF statistics that are considered in engineering design. The data in Figures 2 and 3 show how short duration extreme rainfall statistics have decreased at two Toronto region climate stations, considering IDF updates between 1990 and 2013, as new lower annual observed extreme rainfall totals have been factored into the frequency analyses.

\begin{tabular}{|c|c|c|c|c|c|}
\hline \multicolumn{6}{|c|}{$\begin{array}{l}\text { Toronto Extreme Rainfall Trends } \\
\text { Environment Canada Climate Station } 6158355 \text { (Toronto City) }\end{array}$} \\
\hline \multirow{2}{*}{$\begin{array}{l}\text { Return } \\
\text { Period } \\
\text { (Years) }\end{array}$} & \multicolumn{3}{|c|}{$\begin{array}{l}5 \text { Minute Rainfall Intensity } \\
\qquad(\mathrm{mm} / \mathrm{hr})\end{array}$} & \multicolumn{2}{|c|}{$\begin{array}{l}\text { Change in Rainfall } \\
\text { Intensity }\end{array}$} \\
\hline & $\begin{array}{l}\text { Up to } \\
1990\end{array}$ & $\begin{array}{l}\text { Up to } \\
2003\end{array}$ & $\begin{array}{l}\text { Up to } \\
2007\end{array}$ & $\begin{array}{l}1990- \\
2003\end{array}$ & $\begin{array}{c}1990- \\
2007\end{array}$ \\
\hline 2 & 113.9 & 110.8 & 109.2 & $-2.7 \%$ & $-4.1 \%$ \\
\hline 5 & 159.4 & 154.4 & 151.9 & $-3.1 \%$ & $-4.7 \%$ \\
\hline 10 & 189.6 & 183.3 & 180.1 & $-3.3 \%$ & $-5.0 \%$ \\
\hline 25 & 227.7 & 219.8 & 215.8 & $-3.5 \%$ & $-5.2 \%$ \\
\hline 50 & 256 & 246.8 & 242.3 & $-3.6 \%$ & $-5.4 \%$ \\
\hline \multirow[t]{2}{*}{100} & 284 & 273.7 & 268.5 & $-3.6 \%$ & $-5.5 \%$ \\
\hline & & & Overall: & $-3.3 \%$ & $-5.0 \%$ \\
\hline
\end{tabular}

Figure 2 Downtown Toronto IDF trends 1990-2007 showing lower 5 min intensities across all return periods. 


\begin{tabular}{|c|c|c|c|c|c|c|c|}
\hline \multicolumn{8}{|c|}{$\begin{array}{l}\text { Mississauga Extreme Rainfall Trends } \\
\text { nt Canada Climate Station } 6158733 \text { (Pearson Int'I Airport) }\end{array}$} \\
\hline \multirow{2}{*}{$\begin{array}{l}\text { Return } \\
\text { Period } \\
\text { (Years) }\end{array}$} & \multicolumn{4}{|c|}{5 Minute Rainfall Intensity (mm/hr) } & \multicolumn{3}{|c|}{ Change in Rainfall Intensity } \\
\hline & $\begin{array}{l}\text { Up to } \\
1990\end{array}$ & $\begin{array}{l}\text { Up to } \\
2003\end{array}$ & $\begin{array}{l}\text { Up to } \\
2007\end{array}$ & $\begin{array}{l}\text { Up to } \\
2013\end{array}$ & $\begin{array}{c}1990- \\
2003\end{array}$ & $\begin{array}{c}1990- \\
2007\end{array}$ & $\begin{array}{c}1990- \\
2013\end{array}$ \\
\hline 2 & 107.4 & 100.8 & 100 & 101.9 & $-6.1 \%$ & $-6.9 \%$ & $-5.1 \%$ \\
\hline 5 & 141.5 & 134.7 & 133.2 & 135.2 & $-4.8 \%$ & $-5.9 \%$ & $-4.5 \%$ \\
\hline 10 & 164.2 & 157.3 & 155.2 & 157.3 & $-4.2 \%$ & $-5.5 \%$ & $-4.2 \%$ \\
\hline 25 & 192.7 & 185.7 & 183 & 182.2 & $-3.6 \%$ & $-5.0 \%$ & $-5.4 \%$ \\
\hline 50 & 213.9 & 206.8 & 203.6 & 206 & $-3.3 \%$ & $-4.8 \%$ & $-3.7 \%$ \\
\hline \multirow[t]{2}{*}{100} & 235 & 227.7 & 224 & 226.5 & $-3.1 \%$ & $-4.7 \%$ & $-3.6 \%$ \\
\hline & & & & Overall: & $-4.2 \%$ & $-5.5 \%$ & $-4.4 \%$ \\
\hline
\end{tabular}

Figure 3 Mississauga (Pearson International Airport) IDF trends 1990-2013 showing lower 5 min intensities across all return periods.

Data show that even when the extreme 2013-07-08 rainfall event is considered in the Mississauga 2013 IDF update (Figure $3)$, the trend in 5 min rainfall intensities is downward for all return periods from $2 \mathrm{y}$ to $100 \mathrm{y}$. The Downtown Toronto and Mississauga-Pearson International Airport trends for $15 \mathrm{~min}$ and $1 \mathrm{~h}$ durations (not shown) are also consistently negative, indicating lower rainfall intensities, again for all return periods. Thus the new weather realities may in fact be less severe than the old ones, contrary to System 1 declarations.

The trend in derived IDF values should not be unexpected given the downward annual maximum observation trends for these stations shown in Figures 2 and 3. The downtown Toronto (Toronto City) station data (not shown) shows decreasing maximum rainfall observations for all durations $\leq 24 \mathrm{~h}$, and the $6 \mathrm{~h}$, $12 \mathrm{~h}$ and $24 \mathrm{~h}$ decreases are statistically significant. The Mississauga (Pearson International Airport) trends shown in Figure 4 are more mixed. IDF values are increasing relative to 1990 , but the overall trend is downward for short durations, although at a lower rate. When 2014-2016 data are incorporated, the decline continues as no extreme events occurred during these recent years. Analysis shows the maximum daily Mississauga rainfall total is declining at a rate of $0.11 \mathrm{~mm} / \mathrm{y}$ between 1950 and 2016 and this trend is reflected in the Environment and Climate Change Canada's declining 24-hour IDF values which are shown in Figure 4.

\begin{tabular}{|c|c|c|c|c|c|c|c|}
\hline \multicolumn{7}{|c|}{ Mississauga Extreme Rainfall Trends } \\
\hline \multicolumn{7}{|c|}{ Environment Canada Climate Station 6158733 (Pearson Int'I A) } \\
\hline $\begin{array}{c}\text { Return } \\
\text { Period } \\
\text { (Years) }\end{array}$ & $\mathbf{2 4}$ Hour Rainfall Intensity (mm/hr) & \multicolumn{2}{c|}{ Change in Rainfall Intensity } \\
\cline { 2 - 8 } & $\mathbf{1 9 9 0}$ & $\mathbf{2 0 0 3}$ & $\mathbf{2 0 0 7}$ & $\mathbf{2 0 1 3}$ & $\mathbf{2 0 0 3}$ & $\mathbf{2 0 0 7}$ & $\mathbf{2 0 1 3}$ \\
\hline 2 & 2 & 2 & 1.9 & $\mathbf{2}$ & $0.0 \%$ & $-5.0 \%$ & $0.0 \%$ \\
\hline 5 & 2.8 & 2.7 & 2.7 & 2.8 & $-3.6 \%$ & $-3.6 \%$ & $0.0 \%$ \\
\hline 10 & 3.3 & 3.2 & 3.2 & 3.3 & $-3.0 \%$ & $-3.0 \%$ & $0.0 \%$ \\
\hline 25 & 4 & 3.9 & 3.8 & 4 & $-2.5 \%$ & $-5.0 \%$ & $0.0 \%$ \\
\hline 50 & 4.6 & 4.3 & 4.3 & 4.5 & $-6.5 \%$ & $-6.5 \%$ & $-2.2 \%$ \\
\hline 100 & 5.1 & 4.8 & 4.7 & 5 & $-5.9 \%$ & $-7.8 \%$ & $-2.0 \%$ \\
\hline & & & & Overall: & $-3.6 \%$ & $-5.2 \%$ & $-0.7 \%$ \\
\cline { 5 - 9 }
\end{tabular}

Figure 4 Mississauga (Pearson International Airport) IDF trends 1990-2013 showing lower $24 \mathrm{~h}$ intensities across all return periods.
The lack of recent extreme events from 2014 to 2016 has caused the Mississauga 100 y $24 \mathrm{~h}$ rainfall volume of $119.5 \mathrm{~mm}$ to decrease to $118.3 \mathrm{~mm}$, according to expanded IDF analysis by the City of Markham.

While the estimation of future climate extreme rainfall frequency can rightly be described as a wicked problem that is difficult or impossible to solve with certainty (e.g. because of various representative concentration pathways, downscaling methods, and so on), indentifying historical rainfall frequency as well as trends and statistical significance is not a wicked problem; such data are readily available and are included in the engineering climate datasets (version 2.3). Therefore exercising the availability heuristic, often to suggest opposite trends, may be more a convenient marketing approach to support interest as opposed to a scientific, evidence based characterization of systems.

\subsection{Anchoring Bias: Flood Damage Losses}

Flood damage is an important factor in the development of flood mitigation strategies and can guide the selection of appropriate investments to limit the frequency and severity of losses. Catastrophic losses across Canada have been increasing in an absolute sense over several decades as shown in Figure 5.

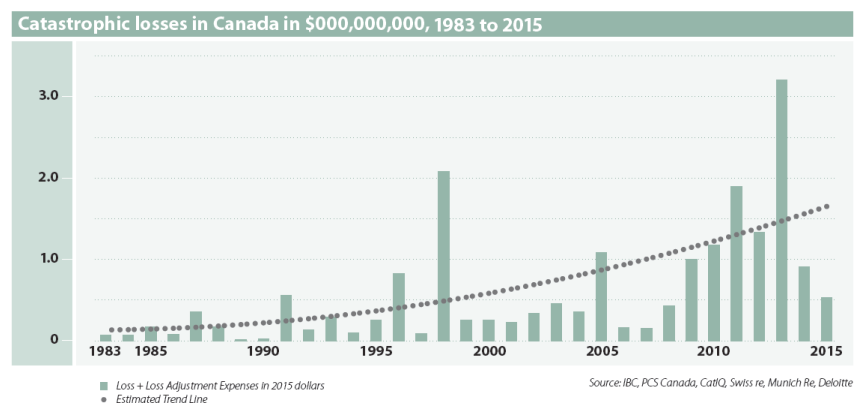

Figure 5 Catastrophic losses in Canada 1983-2015 from the Insurance Bureau of Canada 2016 factbook (IBC 2016).

The increase in losses, and in particular the frequency of severe weather that is associated with several of the loss events, may create an anchoring bias regarding the cause of the losses. The insurance industry has indeed attempted to link these catastrophic losses to the frequency of extreme weather events; in its 2013 factbook the Insurance Bureau of Canada states:

Damage caused by severe weather has emerged in recent years as the leading cause of property insurance claims and now exceeds fire damage in some regions of the country. Environment Canada reports that extreme weather events that used to happen every 40 years can now be expected to happen every six.

IBC 2013

A review of the stated $40 \mathrm{y}$ to $6 \mathrm{y}$ frequency shift (Muir 2016a) has shown the frequency statement to be incorrect and to be based only on a theoretical shift of one standard deviation in a standard normal probability density function (bell curve), and having no basis in Environment Canada's datasets. The statement, originating in Insurance Bureau of Canada's 2012 report Telling the 
Weather Story (IBC 2012), has nonetheless been repeated by major media outlets, the chief economist of a major Canadian bank, and several property and casualty insurers. Environment and Climate Change Canada has recently refuted the frequency statement: In the 2012 report Telling the Weather Story, commissioned to the Institute for Catastrophic Loss Reduction by the Insurance Bureau of Canada, Professor Gordon McBean writes: "Weather events that used to happen once every 40 years are now happening once every six years in some regions in the country." A footnote cites Environment Canada intensity-duration-frequency tables and graphs. However, a spokesperson for Environment and Climate Change Canada told Canadian Underwriter that ECCC's studies "have not shown evidence to support this statement."

Meckbach 2016

An explanation of why a simplistic approach to explaining a complex problem might be considered was provided by Kahneman (2003) when he noted that "People are not accustomed to thinking hard, and are often content to trust a plausible judgment that comes to mind." To explain increased catastrophic losses by increasing rainfall frequency is certainly plausible, despite the contradictory data.

Given that IDF trends are generally flat, further examination of the catastrophic loss trends is warranted. It has been suggested that rising losses in the United States may be driven by factors such as the growth in gross domestic product or insurance market penetration (Pielke 2014). A review of catastrophic losses in Canada, normalized by net written premiums, suggests that increasing loss trends may indeed be partially explained by growth in the insurance market over decades. For example, in 1990 , the value of net written premiums for personal property was $\$ 2.272$ billion while in 2015 it had increased to $\$ 10.187$ billion, almost $450 \%$. When the catastrophic losses from Figure 5 are normalized by the value of the net written premiums, as shown in Figure 6, the rate of increase appears flatter with the greatest normalized losses occurring in 1998.

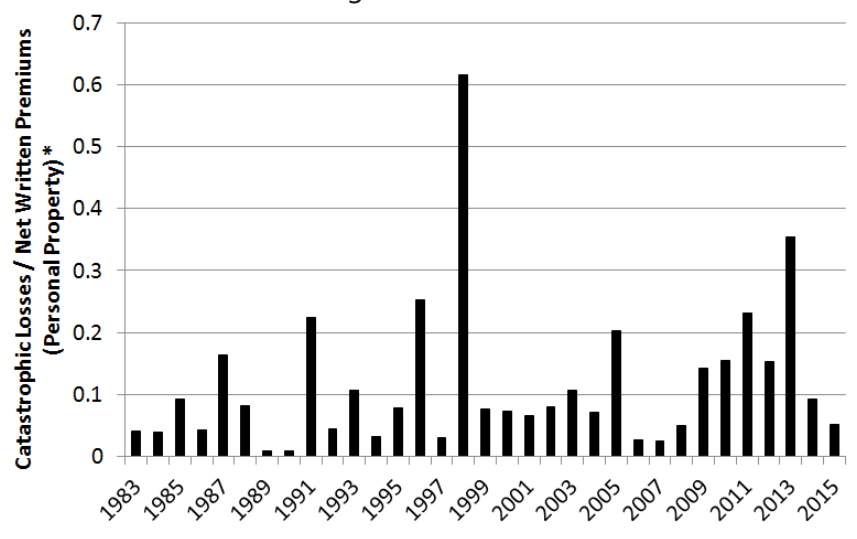

* Catastrophic Losses in 2015 Dollars and NWP (1992-2015) per IBC 2016 Fact Book, NWP (1990-1991) per IBC 2013 Fact Book, NWP 1983-1989 extrapolated assuming $2 \%$ growth per year.

Figure 6 Catastrophic losses in Canada 1983-2015, normalized by insurance market growth (net written premiums for personal property).
This analysis does not suggest that the levels of catastrophic losses are acceptable, nor that they warrant greater or lesser attention. But it does serve to illustrate that the trend in losses may reflect economic growth and an expansion of the insurance market, as opposed to questionable trends in extreme weather events. By accurately characterizing the causes of increased catastrophic losses, a more appropriate and effective solution might be determined, consistent with an evidence based policy approach.

\subsection{Attribute Substitution: Meteorology vs Hy- drology}

The current societal concern with climate change, together with associations and anchoring biases between temperatures and extreme rainfall trends, have caused many people to discount a broader range of risk factors in the analysis of urban flooding events and insurance losses.

Water resources and municipal engineers well understand that the meteorology of extreme rainfall is but one risk factor in the analysis. Hydrology is obviously another risk factor affecting how rainfall (shown to be no more severe than it used to be in Southern Ontario and not a key factor) generates flow loadings within urban drainage systems. However, the discipline of hydrology receives relatively less attention than other factors in terms of explaining urban flood risks. One of Canada's most respected hydrologists, the late Vit Klemeš, surmised why:

The unsatisfactory state of hydrology is, in the final analysis, the result of the dichotomy between the theoretical recognition of hydrology as a science in its own right and the practical impossibility of studying it as a primary discipline but only as an appendage of hydraulic engineering, geography, geology, etc.

\section{Klemeš 1986}

The more recent attribute substitution, which results in an increasing focus on meteorological as opposed to hydrological risk factors, could be reversed if the importance of urbanization trends were to be emphasized. While rainfall intensities have decreased, according to Environment and Climate Change Canada engineering climate datasets, over recent decades, runoff risk factors show dramatic and measurable increases over the same period.

GIS analysis of urban growth (Muir 2016b), as shown in Figure 7 and Table 2, can quantify the Toronto area trends. This analysis makes use of the Ontario government's SOLRIS Version 1.2 land cover GIS mapping, as compiled in the Ontario Land Cover Compilation v.2.0 to represent current land use conditions, and 1966 land use mapping digitized by Ducks Unlimited to represent earlier conditions. 


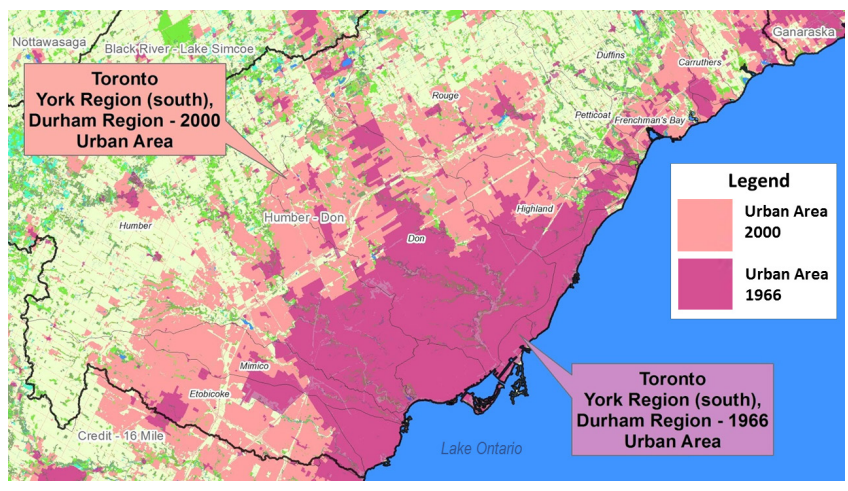

Figure 7 Urbanization trends in the Greater Toronto Area (GTA), 1966 to 1999-2002, as a factor in urban flood risk.

Table 2 Urbanization growth in Toronto area watersheds, 1966 to $1999-2002$, as a factor in urban flood risk.

\begin{tabular}{lccc}
\hline \multicolumn{1}{c}{ Watershed } & Urbanized Area 1966 & $\begin{array}{c}\text { Urbanized Area 1999- } \\
2002\end{array}$ & $\begin{array}{c}\text { Increase in Urban } \\
\text { Coverage }\end{array}$ \\
\hline Near Shore & $19.1 \%$ & $98.9 \%$ & $419 \%$ \\
Highland & $39.4 \%$ & $88.4 \%$ & $124 \%$ \\
Petticoat & $6.0 \%$ & $21.6 \%$ & $258 \%$ \\
Frenchman's Bay & $19.1 \%$ & $84.3 \%$ & $342 \%$ \\
Mimico & $37.6 \%$ & $88.5 \%$ & $135 \%$ \\
Carruthers & $10.8 \%$ & $35.7 \%$ & $230 \%$ \\
Duffins & $2.0 \%$ & $16.3 \%$ & $696 \%$ \\
Rouge & $4.0 \%$ & $43.4 \%$ & $986 \%$ \\
Etobicoke & $14.4 \%$ & $63.6 \%$ & $341 \%$ \\
Humber & $11.7 \%$ & $33.1 \%$ & $183 \%$ \\
Don & $51.3 \%$ & $81.7 \%$ & $59 \%$ \\
\hline
\end{tabular}

Table 2 illustrates that over $\sim 30 \mathrm{y}$, urbanization has increased to almost 10 times the 1966 coverage in the Rouge River watershed, and to 7 times in the Duffins Creek watershed. In Toronto area watersheds, the increase is also dramatic in terms of the absolute coverage. The Highland Creek watershed increased by an added $124 \%$ over the 1966 coverage, resulting in over $88 \%$ urbanization. Similarly, the Mimico Creek watershed urban areas expanded by $135 \%$, also resulting in over $88 \%$ urbanization by 1999-2002. It is recognized that urbanization over some of this growth period has been accompanied by stormwater controls to mitigate peak flow impacts. Nonetheless, urban flood risks due to hydrologic changes may increase in specific drainage systems, especially during events that exceed the capacity of any established controls. This risk factor should be considered in any assessment of increased flood losses and appears more critical than perceived rainfall intensity trends.

While a recent survey of Canadian municipalities by the University of Guelph identified aging infrastructure, climate change, and urbanization as primary drivers of risk to water infrastructure (De Lange et al. 2016), the significant quantifiable factors appear to be aging infrastructure design standards (and not age itself), and urbanization within those high-stress areas with limited standards (and not urbanization in new urban areas). In Markham, Ontario, for example, pre-1980 serviced subdivisions with limited design standards reported 60 times higher flood density compared to more highly impervious, but more resiliently designed post-1990 serviced subdivisions. While urbanization has a demonstrated impact on flood hydrology (Muzik 1993), in some regions change in rainfall intensity has not. After recent expansion of the engineering climate dataset version 2.3 to include records up to 2016, IDF frequency analysis for Buttonville Airport, Markham shows a 30\% decrease in 100 y rainfall intensities of $<30$ min duration.

Perceived climate change shifts in extreme weather frequency or severity are a common explanation of flood risk. Referencing Ottawa region flooding in 2017, Hodgson (2018) notes "It is hard to ignore the growing relationship between climate change and the resulting impact of severe flooding events." Yet the critical importance of hydrologic factors and the impact of urbanization on observed runoff coefficients, and consequently flooding events, has been documented by others as shown in the title of Dickinson and Rudra (2017): “Disentangling Impacts of Climate \& Land Use Change on Quantity \& Quality of River Flows in Southern Ontario." Correcting attribute substitution would contribute to disentangling the causes of flooding and encourage a focus on mitigation measures.

\subsection{Attribute Substitution: Operational vs Tech- nical Risks}

Flooding events may be caused by operational as well as other fundamental technical risk factors. Typically these operational factors are not considered in the explanation of events and a substitution of other technical factors is made. Recent examples in the Toronto area include the Union Station flooding of 2012-0601 and the 2013-07-08 stranded GO (commuter) train, which have operational factors related to flood risks.

On 2012-06-01, Union Station, a major commuter hub in Toronto, was flooded during a rainfall event. At a subsequent presentation to The Empire Club of Canada, the flood event was described as an example of more extreme weather by the insurance industry. The City of Toronto, however, acknowledged that the flooding was due to an operational constraint, related to bypass pumping limitations during construction of maintenance holes. The City's Engineering and Construction Services subsequently updated the Standard Specifications for Sewers and Watermains, TS 4.01 (City of Toronto 2013) in order to expand the bypass capacity requirement to mitigate flood risks during construction.

On 2013-07-08, the Richmond Hill GO train carrying 1400 passengers and crew was stranded in the Don River floodplain during a rainfall event. Emergency services were deployed to evacuate train passengers by boat over a $7 \mathrm{~h}$ period. The rail operator stated in media reports that this was an "unprecedented circumstance" (Kalinowski 2013). The acting Environmental Commissioner of Ontario cited the incident as an example of climate 
change induced extreme weather flood damage in a 2015 press release:

The report [Feeling the Heat] notes that extreme weather associated with climate change has already damaged the province's infrastructure; for example, intense storms and flash floods in recent years have caused costly damage to provincial roadways and commuter rail lines.

Environmental Commissioner of Ontario 2015

Local data and reports show that the 2013-07-08 flood conditions were in fact not unprecedented and that the incident was a reflection of operational decisions as opposed to extreme flood conditions. The Toronto and Region Conservation Authority's (TRCA 2016) Don River hydrology report shows the recorded flood peak of $180 \mathrm{cms}$ on 2013-07-08 at the adjacent Todmorden flow gauge had $\mathrm{a}<5$ y return period. Furthermore, an even higher flood peak of $190 \mathrm{cms}$ had occurred weeks earlier on the early morning of 2013-05-29, but missed the Richmond Hill GO train because of the train's schedule. As such, conditions were not unprecedented and train frequency explained the flood risk as much as rain frequency. Details on recorded water levels and flow rates are provided by Muir (2015).

A 1981 flood inquiry by Lorant further documented known railway line flood risks in the area including the Great Flood on 1878-09-13, the spring of 1914, and during two storms in 1980-03 and 1980-04. Limited flooding was also reported on 1981-05-11 including the area of the Bayview Extension and the Toronto Brick yards where the GO train was stranded in 2013. The flood inquiry report indicates that train operation had previously been halted, or trains were detoured during floods, several times, including 1979-12-25, 1980-01-11, 1980-03-21, 1980-04-14, 1981-02-11 and 1981-05-11. It is possible that the rail operator was not fully aware of the flooding risks, even though the Richmond Hill GO service began in 1978. Nonetheless, records suggest that flood risks were not unprecedented (Muir 2015).

\subsection{What You See Is All There Is: Urban Water Balance and Watercourse Baseflow}

Water resources and municipal engineering practitioners rely on conceptual and model representations of physical systems and processes to analyse diverse water systems and to solve problems, such as achieving flood mitigation and other water management goals. The complexity of these problems and the need for models was effectively described by James:

Models are used to resolve problems.

A problem is a difficult and doubtful matter requiring solution; it is something that is hard to understand, or accomplish, or deal with (Oxford Dictionary of Current English). Thus problems have to do with complexity, and since models (the word model is synonymous with concept) are used to help resolve problems, models are inherently tied up with complexity.

James 2005

The inherent complexity in modeling can result in System 1 analysis short-cuts. As a result, practitioners should strive to reassess fundamental modeling assumptions in their work. James further noted that "It is fundamentally irresponsible and unethical for modelers not to interpret the inherent uncertainty of their model output."

Currently, there is renewed interest in Ontario in urban water balance management as a means to improve water quality and to address perceived or anticipated climate change risks. Accordingly, the Ontario Ministry of the Environment and Climate Change is currently developing LID guidance to mitigate the impacts of past and future urbanization on water systems. The climate change section in the draft document states the goals and requirements for good design as follows:

A primary goal in urban stormwater design is to maintain the existing hydrologic conditions while mitigating property damage or loss of life under extreme conditions. A central requirement for good urban stormwater design is a clear understanding of the hydrologic setting of the development within the context of the surrounding watershed.

MOECC 2017, ch. 6

A critical assessment of the hydrologic settings of urbanized watersheds with regard to water balance impacts and baseflows suggests that the fundamental model representations of urbanized Ontario systems and some key performance characteristics are incorrect; that is, the hydrologic setting is not well understood. While it is assumed that recharge has declined in existing urban areas and that baseflow has also declined, in fact monitoring data show that in local systems the opposite has occurred. For example, while in the Rouge River watershed urban area has increased from 4.0\% to $43.4 \%$ from the mid 1960 s to the late 1990s, as shown in Table 2 above, the baseflow has also increased. Specifically, over this same period the average summer flow has increased by $221 \%$ in the Rouge River and 33\% in the Little Rouge River. Similarly, urbanization of the Highland Creek watershed has increased from $39.4 \%$ to $88.4 \%$ over the period while average summer flow has increased by $351 \%$. The baseflow in the watershed is also increasing and as stated in the Approved Assessment Report:

These overall increases to baseflow volumes are contrary to the common thought that increased impervious cover leads to reduced baseflow

TRCA 2016

An earlier detailed study of baseflow records intended to confirm issues and inform LID and water balance management goals concluded that "urban development does not necessarily result in significant reductions in base flow" (TMIG 2010).

The need for LID in mitigation of urban water balance impacts may be overstated in the draft Ontario policy, at least in terms of the baseflow management goals of many systems. While models that are based on some assumptions and conceptual representations of urban drainage systems may predict the effects of urbanization on recharge and baseflows, monitoring data does not always support the core assumptions. This mis-scoping of the urban water balance problem and the presumed need for LID mitigations recalls Kahneman's WYSIATI bias: if a model simplistically accounts only for recharge losses and not for other processes 
that result in the documented baseflow gains in the system, the model can only and will only predict losses despite the underlying observed behaviour.

Proper identification of problems should be considered to be the key first step in developing evidence based policies. In the case of LID policies the cost of implementation must also be carefully considered together with any adverse impacts of implementation. Within existing urbanized areas, LID technologies have been used on limited spatial scales and only limited sets of performance benefits have been considered. Adverse system-wide effects such as the impacts on existing infrastructure and property are typically excluded from consideration, suggesting Kahneman's pervasive optimism bias and inadequate problem scoping. Some authorities like the Seattle Public Utilities have recognized the adverse impacts of LID implementation and employ impermeable liners as noted in the development of the Street Edge Alternatives project:

Our original hope for retaining flows and allowing infiltration into the native soils throughout the length of the block was not possible because some homes had an existing groundwater intrusion problem. To limit the potential for stormwater to adversely impact the residences of concern, our geotechnical engineers identified some swales that needed an impermeable liner.

Seattle Public Utilities 2016

The U.S. Transportation Research Board, in its Evaluation of Best Management Practices for Highway Runoff Control, has also identified wastewater inflow and infiltration risks with LID infiltration practices in urban areas:

In urban areas, unrestricted infiltration may exacerbate infiltration and inflow (I/I) problems in both separate and combined systems; the likelihood of this scenario must be evaluated before constructing unlined infiltration systems.

Transportation Research Board 2006

The potential impacts have been known for some time in Ontario. The former Ministry of the Environment conducted a workshop, Stormwater Quality Best Management Practices, in 1992 following the introduction of onsite infiltration source control LIDs called best management practices (BMPs). The comprehensive workshop summary prepared by Marshall Macklin Monaghan Limited identifies concerns with onsite infiltration measures and these include:

- basement leakage problems related to infiltration near housing; and

- surcharging of sanitary sewers by short circuiting of infiltrated water.

The Ontario Municipal Knowledge Network has also recognized the adverse effects of infiltration in terms of basement flood risks and treatment costs (Ontario Centre for Municipal Best Practices 2008). These key impacts have been omitted from Ontario's draft LID Guidance documents but should be considered as a constraint to implementation in existing flood risk prone, high extraneous flow wastewater systems. Recently, the Ontario Superior Court of Justice, court file CV-12-456921, has indicated that groundwater seepage can invalidate insurance coverage for homeowners, even in areas with known wastewater flood risks (e.g. Toronto MCEA Area 29). LID infiltration intended to raise groundwater levels can aggravate seepage.

It has been suggested that the objectives of competitive infrastructure and improved environment may be contradictory and unattainable (James 2000), and that we need to recognize tradeoffs in complex urban systems. When complex problems are assessed with a narrow WYSIATI approach, however, adverse impacts are not even acknowledged for potential evaluation.

\subsection{Attribute Substitution: Site Specific Econom- ics}

Where limited data is available to guide economic evaluations, attribute substitution biases can emerge whereby readily available data for dissimilar sites is substituted for the intended target site. This type of bias has been found in the evaluation of LID retrofit costs for urban areas. The cost savings associated with new construction on estate-residential lots in the rural United States have been wrongly equated to retrofit costs in existing, more densely developed Ontario urban centres.

The MOECC LID guidance climate change report (MOECC 2017) identifies the average cost savings from a USEPA report for rural, large lot subdivisions (e.g., Auburn Hills subdivision, Southwestern Wisconsin; Gap Creek subdivision, Sherwood, Arkansas; Laurel Springs subdivision, Jackson, Wisconsin; Mill Creek subdivision, Kane County, Illinois; Prairie Crossing subdivision, Grayslake, Illinois; Prairie Glen subdivision, Germantown, Wisconsin) that are not relevant to Ontario urban areas and not relevant to many urban roadway retrofits (USEPA 2007). The USEPA cost savings relate to the use of swales instead of storm sewers in the rural subdivisions, considering built-form densities that would not be supported in Ontario's Places to Grow Act.

Canadian studies cited in the USEPA report indicate that the LID implementation on Crown Street, Vancouver, BC, a street redevelopment project, added $79 \%$ to the capital cost and consultant design fees (added capital cost $\$ 396 \mathrm{k}$; consultant and aesthetic design features cost $\$ 311 \mathrm{k}$ ). This is contrary to the $25 \%$ savings suggested by MOECC. More recently, in Ontario the 2016 Markham Green Road tender costs revealed that LID features added over $37 \%$ to the conventional road design, approximately $\$ 1.3 \mathrm{million} / \mathrm{km}$. Demonstration project costs in Ottawa had even higher average incremental costs of $\$ 1.5$ million $/ \mathrm{km}$ (Conway 2017). Thus there were in fact no savings in these high density urban settings that were comparable to those identified in the USEPA rural estate lot sites.

When LID retrofit costs are extrapolated across Ontario using GIS land use mapping, as described in section 2.4, and unit costs from recent projects are considered, the capital costs are immense. With a target urban area of 852045 ha, according to the SOLRIS Version 1.2 land cover GIS mapping in the Ontario Land Cover Compilation v.2.0, and a unit cost of $\$ 400000 /$ ha for service area based on completed project tender costs (Muir 2017), the capital cost of the Ontario retrofit is $\$ 340$ billion. This retrofit cost is simply 
prohibitive, given that the entire Ontario stormwater infrastructure deficit has been recently stated to be only $\$ 6.8$ billion (Environmental Commissioner of Ontario 2016). Clearly, LID implementation costs on this scale, which could significantly affect a province's or a municipality's long term finances, require thorough and careful input from not only the engineering community involved in local, small scale technical studies, but also economists and public administrators who can bring a broader perspective on priorities, surrounding issues and solutions. Given the absence of existing baseflow issues in many Toronto area watercourses, the prescribed cure may in fact be more harmful than the disease.

\subsection{Attribute Substitution: Application of IDF Data vs Hyetographs or Design Storms}

Continuing attention is given to intensity-duration-frequency (IDF) curves due to perceived and anticipated shifts in extreme rainfall severity due to climate change. This is despite national datsets that show overall flat trends and decreasing extreme value statistics in some regions. Various methods of extrapolating and downscaling future IDF statistics have been suggested and are described by the Canadian Standards Association (CSA 2012). Ness (2015) noted that "incorporating climate change into IDF is highly uncertain. Different approaches will generate different results." Coulibaly et al. (2016) noted that "there is still significant variability among future IDF statistics. In some cases, datasets diverge in the direction of change projected." Thus there is a wicked problem that is not readily solved.

The importance of IDF curves in the context of many urban flooding problems has been overstated given that hyetograph selection, time series rainfall, and historical storms govern the assessment and design of complex infrastructure and watershed systems. While sensitivity analysis has shown that in Southern Ontario projected IDF increases may be in the order of $20 \%$ (Simonovic and Peck 2009), in Toronto hyetograph selection can increase peak flows in small urban catchments by $100 \%$. Short duration intensities may be clipped in the derivation of hyetyographs used in Toronto area floodplain mapping, as shown in Figure 8. The emphasis placed on uncertain IDF input data should be reviewed in the light of other design factors.

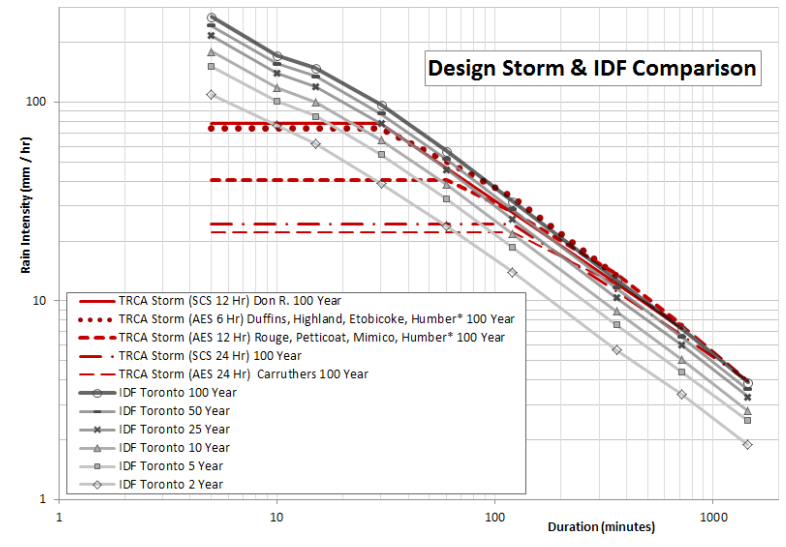

Figure 8 IDF and design hyetograph comparison for Toronto area.

\section{Conclusions}

Analytical tools are a necessity for urban flood management and water management. The systems to be analysed are complex and the issues that need to be addressed and the key risk factors may not be readily defined. As has been shown, trends in catastrophic losses that are shown to increase dramatically in an absolute sense may not be increasing dramatically when adjusted for insurance market growth over decades. Thus the issue of urban flood damages and the need for appropriate mitigation can be prioritized based on a data driven evidence based approach that considers normalized trends. Such a rigorous approach can help to overcome anchoring biases associated with incomplete problem definition. A review of risk factors affecting urban flooding has shown that Kahneman's System 1 Thinking Fast anchoring biases and availability heuristics can misdirect attention toward less relevant risk factors, in comparison to a methodical statistically robust System 2 Thinking Slow. Key anchoring biases include the misassociation of increasing temperature trends with decreasing extreme rainfall trends in Southern Ontario. Key availability heuristic biases include the listing of extreme events as a surrogate for proper trend analysis using the engineering climate datasets. Attribution substitution biases were shown to be apparent in the definition of risk factors and policy guidance. These include the emphasis on meteorological drivers to explain flood risks in place of obvious hydrological drivers, and the emphasis on climate change drivers to explain flood incidents in place of well-documented operational considerations. Given the shortcomings identified in this review, effective evidence based policies and sound engineering solutions to water management problems require renewed adherence to Thinking Slow on floods and flow to achieve accurate problem definition and accurate identification of key risk factors.

\section{References}

Bullock, H., J. Mountford and R. Stanley. 2001. Better Policy Making. London: Centre for Management and Policy Studies, Policy Studies Directorate.

Bumstead, J. M. 2002. "The Manitoba Royal Commission on Flood Cost Benefit and the Origins of Cost-Benefit Analysis in Canada." American Review of Canadian Studies 32 (1): 97.

Conway, D. 2017. City of Ottawa. 2017. Roadway bioretention retrofit implementation costs for Sunnyside (179 m long, one side only) and Stewart (243 m long) projects. D. Conway, City of Ottawa, personal communication.

City of Toronto. 2013. Standard Specifications for Sewers and Watermains. Toronto: City of Toronto Engineering and Construction Services Division, TS 4.01.

https://www.toronto.ca/wp-content/uploads/2017/11/97d2-ecs-specs-pipeas-TS_4.01_Apr2013. pdf

Coulibaly, P., D. H. Burn, H. Switzman, J. Henderson and E. Fausto. 2016. A Comparison of Future IDF Curves for Southern 
Ontario: Addendum —IDF Statistics, Curves and Equations. Toronto: Ontario Climate Consortium. https:/climateconnections.ca/wp-content/uploads/2014/01/IDF-Comparison-Report-and-Addendum. pdf

CSA (Canadian Standards Association). 2012. PLUS 4013 Technical Guide-Development, Interpretation and Use of Rainfall Intensity-Duration-Frequency (IDF) Information: Guideline for Canadian Water Resources Practitioners, 2nd ed. Toronto: CSA Group.

De Lange, M., R. Harvey, Y. Wang and E. McBean. 2016. “The Water Utility Risk Integration Matrix: Demonstrating Potential for an Integrated Approach to Municipal Water Management." Journal of Water Management Modeling C396. https://doi.org/10.14796/JWMM.C396

Dickinson, T. and R. Rudra. 2017. Disentangling Impacts of Climate \& Land Use Change on Quantity \& Quality of River Flows in Southern Ontario. Guelph: University of Guelph. https://www.slideshare.net/RobertMuir3/disentangling-impacts-of-climate-land-use-change-on-quantity-quality-ofriver-flows-in-southern-ontario-trevor-dickinson-rameshrudra-university-of-guelph

Edmiston, J. 2013. “'Streets just couldn't dispel the water': Huge storm more than tripled downtown Toronto's rainfall record." Toronto: National Post 2013-07-09.

http://nationalpost.com/posted-toronto/streets-just-couldnt-dispel-the-water-huge-storm-more-than-tripled-downtown-torontos-rainfall-record

Environment and Climate Change Canada. 2015. Engineering Climate Datasets. Ottawa: Government of Canada. ftp://ftp.tor.ec.gc.ca/Pub/Engineering_Climate_Dataset/ IDF/IDF_v2.30_2014-12-21/

Environment Canada, Adaptation and Impacts Research Climate Research Division. 2011. Methodologies to Improve Rainfall Intensity-Duration-Frequency (IDF) Estimates: A Southern Ontario Pilot Study.

Environmental Commissioner of Ontario. 2015. Feeling the Heat: 2015 Annual Greenhouse Gas Progress Report-Media Release. Toronto: Environmental Commissioner of Ontario. http://docs.assets.eco.on.ca/reports/climatechange/2015/2015-GHG-Press-release.pdf

Environmental Commissioner of Ontario. 2016. Urban Stormwater Fees: How to Pay for What We Need. Toronto: Environmental Commissioner of Ontario. https://media.assets.eco.on.ca/web/2016/11/Urban-Stormwater-Fees.pdf

Head, B. 2010. “Evidence-Based Policy: Principles and Requirements." In Strengthening Evidence-Based Policy in the Australian Federation, vol 1, 13-26. Melbourne, VIC: Productivity Commission.

Hodgson, G. 2018. "How We Can Better Mitigate Flood Risk in Canada." Toronto: The Globe and Mail 2018-01-15. https://www.theglobeandmail.com/report-on-business/ rob-commentary/how-we-can-better-mitigate-flood-riskin-canada/article37609942/

IBC (Insurance Bureau of Canada). 2012. Telling the Weather Story. Toronto: Insurance Bureau of Canada.

http://iclr.org/images/Telling_the_weather_story.pdf

IBC (Insurance Bureau of Canada). 2013. Facts of the Property and Casualty Insurance Industry in Canada 2013. Toronto: Insurance Bureau of Canada.

http://assets.ibc.ca/Documents/Facts\%20Book/Facts_Book/ IBC-Facts-2013.pdf

IBC (Insurance Bureau of Canada). 2016. Facts of the Property and Casualty Insurance Industry in Canada 2016. Toronto: Insurance Bureau of Canada.

http://assets.ibc.ca/Documents/Facts\%20Book/Facts_ Book/2016/Facts-Book-2016.pdf

James, W. 2000. “Towards Smart, Benign Urban Water Infrastructure." Journal of Water Management Modeling R206-02. https://doi.org/10.14796/JWMM.R206-02

James, W. 2005. Rules for Responsible Modeling, 4th ed. Guelph: $\mathrm{CHI}$ Press. https://doi.org/10.14796/JWMM.R184

James, W., T. El-Hosseiny, H. Whiteley. 1998. “On the Optimization of Uncertainty Complexity and Cost for Modeling Combined Sewer Systems." Journal of Water Management Modeling R200-08.

https://doi.org/10.14796/JWMM.R200-08

Kahneman, D. 2003. “Maps of Bounded Rationality: Psychology for Behavioral Economics". American Economic Review 93 (5): 1449-75.

Kahneman, D. 2011. Thinking, Fast and Slow. Toronto: Random House of Canada.

Kalinowski, T. 2013."GO Transit Offers Riders on Flood-Stranded Richmond Hill Train \$100 Credit." Toronto: The Star 2013-0710.

https://www.thestar.com/news/gta/2013/07/10/go_transit_offers_riders_on_floodstranded_richmond_hill_ train_100_cred it.html

Klemeš, V. 1986. “Dilettantism in Hydrology: Transition or Destiny?" Water Resources Research 22 (August): S177-88. https://doi.org/10.1029/WR022i09Sp0177S

MEA (Municipal Engineers Association). 2015. Municipal Class Environmental Assessment (MCEA), October 2000, as amended in 2007, 2011 \& 2015. Oakville, ON: Municipal Engineers Association.

Meckbach, G. 2016. "New IBC Flood Model Shows 1.8 Million Canadian Households At 'Very High Risk".' Toronto: Canadian Underwriter 2016-02-02.

https://www.canadianunderwriter.ca/insurance/new-ibcflood-model-shows-1-8-million-canadian-households-atvery-high-risk-1004006457/ 
MOECC (Ontario Ministry of the Environment and Climate Change). 2015. Ontario's Climate Change: Discussion Paper 2015. Toronto: Ontario Ministry of the Environment and Climate Change. http://www.downloads.ene.gov.on.ca/envision/env_reg/ er/documents/2015/012-3452.pdf

MOECC (Ontario Ministry of the Environment and Climate Change). 2017. Draft: Low Impact Development (LID) Stormwater Management Guidance Manual. Toronto: Ontario Ministry of the Environment and Climate Change. http://www.municipalclassea.ca/files/7_DRAFT_MOECC_ LID\%20SWM\%20Manual.pdf

Muir, R. J. 2015. “Toronto GO Train Flood Avoidable July 8, 2013Worse May 29, 2013 Flood Ignored." Toronto: R. J. Muir. http://www.cityfloodmap.com/2015/12/stranded-metrolinx-go-train-avoidable.html

Muir, R. J. 2016a. Review of Weather Event Statement in Insurance Bureau of Canada's Telling the Weather Story prepared by Institute for Catastrophic Loss Reduction. Toronto: R. J. Muir. https://www.slideshare.net/RobertMuir3/storm-intensity-not-increasing-factual-review-of-engineering-datasets

Muir, R. J. 2016b. Secret is Out! Urbanization and Runoff Explain Increased Urban Flood Risk in Southern Ontario. Toronto: R. J. Muir. http://www.cityfloodmap.com/2016/08/urbanization-and-runoff-explain.html

Muir, R. J. 2017. National Water \& Wastewater Benchmarking Initiative Stormwater Task Force: LID Design Tool and Lifecycle Costing. Markham, ON: The Corporation of the City of Markham. https://drive.google.com/open?id=1q_itvH2A1_354HvfRqFGivBZULb8LgBI

Muzik, I. 1993. "Application of a GIS to Assess Changes in Flood Hydrology of Urbanizing Watersheds." Journal of Water Management Modeling R175-20. https://doi.org/10.14796/JWMM.R175-20

Ness, R. 2015. “Rainfall IDF: New Developments and Incorporating Climate Change." Presented at Southern Ontario Municipal Stormwater Discussion Group Meeting, Vaughan, Ontario.

O'Connor, D. R. 2002. Part Two Report of the Walkerton Inquiry: A Strategy for Safe Drinking Water. Toronto: Ontario Ministry of the Attorney General.

http://www.archives.gov.on.ca/en/e_records/walkerton/ report2/index.html

Ontario Centre for Municipal Best Practices. 2008. Best Practice Summary Report: Water and Sewer-General Inflow and Infiltration Management Practices. Toronto: Ontario Centre for Municipal Best Practices. http://www.omkn.ca/OMKN-Docs/Best-Practices/ Water-and-Wastewater/2008/OMBI_General-II-Management_Practices_Feb2008_Final.aspx
Ontario Ministry of Infrastructure. 2017. Building Better Lives: Ontario's Long Term Infrastructure Plan 2017. Toronto: Queen's Printer for Ontario.

https://www.ontario.ca/document/building-better-livesontarios-long-term-infrastructure-plan-2017

Pielke, R., Jr. 2014. The Rightful Place of Science: Disasters and Climate Change. Tempe, AZ: Arizona State University Consortium for Science, Policy \& Outcomes.

Seattle Public Utilities. 2016. Street Edge Alternatives: Drainage Improvements. Seattle, WA: Seattle Public Utilities. http://www.seattle.gov/UTIL/EnvironmentConservation/ Projects/GreenStormwaterInfrastructure/CompletedGSIProjects/StreetEdgeAlternatives/index.htm

Shephard, M. W., E. Mekis, R. J. Morris, Y. Feng, X. Zhang, K. Kilcup and R. Fleetwood. 2014. "Trends in Canadian Short-Duration Extreme Rainfall: Including an Intensity-Duration-Frequency Perspective." Atmosphere-Ocean 52 (5): 398-417. https://doi.org/10.1080/07055900.2014.969677

Simonovic, S. and A. Peck. 2009. Water Resources Research Report: Updated Rainfall Intensity Duration Frequency Curves for the City of London Under the Changing Climate. London, ON: The University of Western Ontario, Department of Civil and Environmental Engineering.

https://ir.lib.uwo.ca/cgi/viewcontent.cgi?referer=https:// www.google.ca/\&httpsredir $=1$ \&article $=1027 \&$ context $=$ wrrr

Statistics Canada. 2011. Envirostats: Temperature Trends in Canada. Ottawa: Statistics Canada. 16-002-X. http://www.statcan.gc.ca/pub/16-002-x/16-002-x2011001eng.pdf

TMIG (The Municipal Infrastructure Group Ltd. and BILD Water Balance Subcommittee). 2010. Greater Toronto Area Water Balance Review and Stream Flow Analysis, File 07133

Transportation Research Board. 2006. Evaluation of Best Management Practices for Highway Runoff Control. Washington, DC: Transportation Research Board. NCHRP Report 565. https://www.nap.edu/read/23211/chapter/1

TRCA (Toronto and Region Conservation Authority). 2016. "Surface Water Trends." In Approved Assessment Report: Toronto and Region Source Protection Area, sec 3.4.2. Toronto: Toronto and Region Conservation Authority. http://www.ctcswp.ca/wp-content/uploads/2015/07/ RPT_20150723_Feb2015_TRSPA_PUAR_Chap3_HiRez.pdf

USEPA (U.S. Environmental Protection Agency). 2007. Reducing Stormwater Costs through Low Impact Development (LID) Strategies and Practices. Washington, DC: U.S. Environmental Protection Agency. EPA 841-F-07-006 https://www.h-gac.com/community/low-impact-development/documents/Reducing-Stormwater-Costs-throughLID.pdf 